\title{
11. Measuring Wealth and Welfare: Why HDI and GPI Fail ${ }^{1}$
}

\author{
Ian Castles
}

Earlier this year [1997], the World Bank released World Development Indicators, a comprehensive database of statistics relating to the wealth and welfare of the world's peoples. The new annual publication provided some 600 indicators for nearly 150 countries. In his Foreword to the hard-copy version, the Bank's President, James Wolfensohn, expressed the hope that the new publication

will become the principal mechanism by which the world measures progress in reducing poverty and in enriching the lives of people everywhere. $^{2}$

At the masthead of Chapter 1, the World Bank reproduced the celebrated injunction of Sir William Petty, inventor of the concept of national income, to members of the Royal Society of London - No word might be used but what marks either number, weight or measure. The authors of the new compendium were quick to point out that Petty's concerns went beyond the national income to such factors as 'the Common Safety' and 'each Man's particular Happiness'.

The Bank's invocation of the name and work of Sir William Petty was particularly apt. The underlying principle of his great work Political Arithmetick, written in 1676, was that the condition of England and its people could be represented in numbers. Moreover, Petty argued that these numbers - 'development indicators' in modern terminology - could be applied to 'policy, by the name of Political Arithmetic', and that government had a responsibility to ensure the accuracy of the information upon which policy was founded:

Now the Observations or Positions expressed by Weight and Measure, upon which I bottom the ensuing Discourses, are either true, or not apparently false, and which if they are not already true, certain, and evident, yet may be made so by the Sovereign Power... ...I hope all ingenious and candid persons will rectifie the Errors, Defects and Imperfections, which probably may be found in any of (my) Positions... Nor would it misbecome Authority it self, to clear the Truth of those Matters which private Endeavours cannot reach to. ${ }^{3}$

\footnotetext{
1 First presented in 1997 at the Academy of the Social Sciences annual symposium.

2 World Bank (1997). World Development Indicators, pv.

3 Petty, Sir William (1676). Political Arithmetick in Hull, $\mathrm{CH}$ (ed) The Economic Writings of Sir William Petty, Cambridge, 1899, vol. 1: 244-5. The reference to 'policy by the name of Political Arithmetic' is quoted in Strauss, E (1954). Sir William Petty: Portrait of a Genius: 184.
} 
Generalising from Petty's example, the World Bank authors claimed that 'Since the seventeenth century, economists have viewed development as a means of improving standards of living and the quality of life in very broad terms'. But they did not believe that the 'quality of life' itself could be represented in numbers: the aim of World Development Indicators was to enumerate various indicators of 'life's quality'. Judgements about the relative importance of individual indicators needed to recognise that

...values differ greatly from individual to individual, reflecting different aspirations, conceptions, abilities and tastes - and from society to society, reflecting culture and tradition. ${ }^{4}$

But the World Bank economists did observe that one of the 600 indicators GNP per capita - had a particular significance. They cited the results of a study undertaken jointly by Partha Dasgupta, professor of economics at Cambridge, and Martin Weale, director of Britain's National Institute of Economic and Social Research, which had established 'a strong correlation between the rankings of 48 developing countries for GNP per capita (adjusted for purchasing power parity) and their rankings for five other indicators (life expectancy, infant mortality, adult literacy, political rights and civil rights). ${ }^{5}$

This cross-country study of the relationship between 'quality of life' indicators was used by Professor Dasgupta in his monograph, An Inquiry into Well-Being and Destitution, from which the World Bank authors quoted an important finding:

...recent suggestions that national income is a vastly misleading index are not borne out by this exercise. We can do better than merely rely on national income, but we wouldn't have been wildly off the mark as regards an ordinal comparison of countries had we relied exclusively on national income per head. ${ }^{6}$

The nature of this relationship between national income and other measures of wellbeing and quality of life was a subject of intense interest to our late friend and colleague Fred Gruen, who is sadly missed from the Academy's Symposium this year and who would certainly have been an active participant if he were with us. In a 1996 paper entitled 'The Quality of Life, the National Interest and the Role of Economics', ${ }^{7}$ Fred drew extensively on the study by Weale and Dasgupta, and followed the same methodology to produce 'an assessment of the quality of life in Australia using available comparative surveys'.

4 World Bank (1997), op cit: 3.

5 Dasgupta, Partha and Weale, Martin (1992). 'On Measuring the Quality of Life' in World Development 20: 119-31.

6 Dasgupta, Partha (1993). An Inquiry into Well-Being and Destitution, Oxford.

7 Gruen, Fred (1996). 'The Quality of Life, the National Interest and the Role of Economics'. Contribution to a series of seminars entitled 'Dialogues on Australia's Future' in honour of Professor Ronald Henderson. 
Professor Gruen noted that the Weale and Dasgupta finding of a strong relationship between average real incomes and various aspects of the quality of life in developing countries was confirmed by the evidence used in Ronald Inglehart's monograph Culture Shift in Advanced Industrial Societies, which had identified strong and statistically significant positive relationships between GDP per head and 'mean life satisfaction' in the richer countries. ${ }^{8}$

Professor Gruen took issue with 'arguments advanced in the 1995 Boyer Lectures (and elsewhere) that Australia has neglected such social values as trust, reciprocity and mutuality in a narrow drive for competition and wealth creation' and he concluded that

Cross-national evidence suggests strongly that, in countries with high average real incomes, people tend to believe that 'most people can be trusted'. Practically all studies available so far suggest a positive relationship between real incomes and the various aspects of the quality of life which can be measured. This suggests that the decline in trust in many of Australia's institutions over the years is as likely to have been produced by our poor economic performance - rather than being the result of concentrating too much on wealth creation ... and not enough on 'the quality of life'. 9

It is only in recent years that the availability of internationally comparable real income and quality of life indicators for a large number of countries has enabled relationships between these measures to be tested. The accumulating evidence of strong correlations between these variables is significant, because economists have traditionally been reluctant to draw conclusions about economic welfare, let alone welfare more generally, from macro-economic aggregates.

As long ago as 1912, in his seminal work Wealth and Welfare, AC Pigou, professor of political economy at Cambridge, held that the 'national dividend' is only part of 'economic welfare'; that 'economic welfare is ... a part of a part of (total) welfare'; and that 'anything in the nature of rigid inference from effects on economic welfare to effects on total welfare is out of the question'.. ${ }^{10}$

In 1946, Australia's Dr (later Sir) Roland Wilson took a similar view:

'Well-being' is somewhat wider than 'economic welfare', and 'economic welfare' comprehends more than the market-valued wealth which is the refuge of some economists but the only stock-in-trade of the economic statistician. Even if our productivity measures were all inclusive, and

8 Inglehart, Ronald (1990). Culture Shift in Advanced Industrial Society, Princeton University Press.

9 Gruen, Fred (1996). Op cit, Executive Summary: 2.

10 Pigou, AC (1912). Wealth and Welfare, London: 3-11. 
completely accurate within their limits, it is clear that they would not necessarily serve as complete indexes of well-being, even defined in a quasi-economic sense. ${ }^{11}$

And in 1976 Richard Stone, who had been the chief architect of Britain's official national accounts 35 years earlier, pointed out that:

... the figures ... [of GNP] measure the unduplicated output of goods and services per head of the population ... [But] welfare depends on much besides the availability of produced goods and services: according to the tastes prevailing in different cultures, a good climate, space, tranquility, a sense of security, a sense of freedom, and many other things which do not enter into the national accounts will be prized as well as an abundance of goods and services. However, estimates of output are useful in themselves and are an essential element in any attempt to measure ... welfare. $^{12}$

The evidence from cross-country studies of strong correlations between real GDP per head and other measures of wellbeing might have been expected to provide a strong fillip to the development and maintenance of internationally comparable estimates of GDP and its components. In fact, however, the trend has been all the other way.

In an address to the congress of the International Statistical Institute at Beijing in 1995, Jean-Claude Milleron, Under-Secretary General of the United Nations and former head of INSEE, France's national statistical office, expressed the view that, in this area, 'we cannot continue to be as weak as we are today'. $\mathrm{Mr}$ Milleron nominated the need for 'improved international comparisons of major macroeconomic aggregates' as one of two 'particularly urgent' priorities which called for 'major investigations, both conceptually and empirically' in order to strengthen the global statistical system. ${ }^{13}$

But it was not to be. The Statistics Division of the United Nations can no longer afford to support the International Comparison Project (ICP), which was developed at the University of Pennsylvania in the late 1960s as the major source of internationally comparable price and output data. The importance of this project for researchers into wealth and wellbeing may be judged from the fact that the number of citations of its benchmark monographs and the associated

11 Wilson, Roland (1947). Facts and Fancies of Productivity (Paper read, as a Presidential Address, before Section G of the Australian and New Zealand Association for the Advancement of Science, August 1946), Melbourne: 18 .

12 Stone, JRN and G (1976). National Income and Expenditure, (8th ed), London: 151.

13 Milleron, J-C (1995). 'Global Aspects of a Statistical System in the World Today', Bulletin of the International Satistical Institute: Proceedings, 50th Session: 1759-75. 
Penn World Tables which had been listed in the Social Science Citation Index by early 1995 had exceeded 1000, and the number of different (first) authors represented in the list exceeds $600 .^{14}$

The interest of researchers continues. At the International Statistical Institute meeting in Istanbul last August, an invited papers session on the topic 'International multilateral measurement of purchasing power parities and real income' included a paper by Professor Prasada Rao of the University of New England, one of the newly elected Fellows of the Academy of the Social Sciences [in Australia] who is present at this Symposium; and Professor Alan Heston of the University of Pennsylvania, a leader in ICP research, will participate in a seminar on 'The Asian Economies in the Twentieth Century' at Griffith University later this month.

But the ICP itself is under review and, unless new sources of funds can be found, it will be wound up. Earlier this year, I undertook a review for the OECD of its 'purchasing power parity' program, upon which the ICP relies for its estimates of internationally comparable price and output data for richer countries such as the United States, Japan and Australia. My report, which was discussed at a meeting of national accounts experts in Paris last week, argued that the staffing input of 2.5 staff years which the OECD currently devotes to this program falls far short of the minimum staffing allocation required for the compilation of reliable statistics in this area. The future of this program is also in serious question.

\section{The Human Development Indicator (HDI)}

Whilst the Statistics Division of the United Nations no longer has the funds to support the international comparisons of macro-economic aggregates which Jean-Claude Milleron rightly sees as a vital element in the global statistical system, another arm of the world body - The United Nations Development Program (UNDP) - is able to devote substantial resources to publishing and promoting its own interpretation of the significance of indicators of wellbeing which have been compiled elsewhere.

The UNDP has devised a Human Development Index (HDI), which is calculated annually and published in its Human Development Report. The purpose of the HDI is to compare the relative level of 'human development' of the peoples of the world. Specifically, the HDI

14 Information provided by Professor Robert Summers, from a citation list prepared in mid-1995 for a proposal submitted to the US National Science Foundation. 
...measures the average achievements in a country in three basic dimensions of human development - longevity, knowledge and a decent standard of living. A composite index, the HDI thus contains three variables: life expectancy, educational attainment (adult literacy and combined primary, secondary and tertiary enrolment) and real GDP per capita (in PPP \$). ${ }^{15}$

The HDI has gained enormous attention, not least because the UNDP presents the results in a way that is calculated to gain maximum attention in the world's media.

By way of contrast, the format of the tables in the World Bank's World Development Indicators is not calculated to win media attention: countries are listed in alphabetical order so that, for most of the 600 indicators, the list begins with Albania and ends with Zaire. If James Wolfensohn is to achieve his hope that the Bank's publication becomes 'the principal mechanism by which the world measures progress...in enriching the lives of people everywhere', the Bank may need to change this form of presentation.

The format in which the Human Development Office of the UNDP presents the annual HDI results is more 'media-friendly': the countries of the world are listed in the order of their assessed performance in the achievement of 'human development'. In 1997, Canada headed the list for the fourth year running, with a score of 960 points out of a possible 1000; whereas Sierra Leone, at the bottom (country number 175), gained only 176 points.

In presenting the annual HDI results, the Human Development Office takes every opportunity to pursue its own agenda. Despite the accumulating evidence of strong correlations between real GDP and other 'quality of life' indicators, the presentation of the HDI results is geared to the promotion of the contrary view.

One technique which is adopted is to include in each year's HDI table a column showing the 'Real GDP per capita rank minus HDI rank'. These differences are highlighted in the text of the Human Development Reports. In the 1997 Report for example, countries whose HDI rank greatly exceeded their GDP rank were praised for 'effectively translat[ing] the benefits of economic growth into improvements in the lives of the people'; and the countries whose GDP rank greatly exceeded their HDI rank were held by the UNDP authors to have 'considerable scope for distributing the benefits of economic growth more equitably'. ${ }^{16}$

15 United Nations Development Program (1997). Human Development Report: 14.

16 Ibid: 46. 
The authors of the Human Development Report are less than candid in arguing for the usefulness and validity of the HDI. In the 1997 Report, for example, the Index was presented as an initiative which has found increasing favour among those concerned with the measurement of human wellbeing:

Although greeted with controversy when first launched in 1990, the HDI has found an increasing following as a simple measure of human development. The HDI provides an alternative to GNP, for assessing a country's standing in basic human development or its progress in human development over time. ${ }^{17}$

Somewhat disingenuously, there was no mention of the judgement on the HDI made by Partha Dasgupta in An Inquiry into Well-Being and Destitution:

...the index is not much good: it has too many unappealing properties ... HDI is also excessively partial. ${ }^{18}$

Professor Dasgupta also expressed the view that the HDI did not have much normative significance, and that when its authors had attempted to give an account of what the normative significance of the index was, they had ended up 'merely describing HDI'. It is important to recognise that these critical assessments of the HDI were concerned solely with the technical properties of the index: Dasgupta's verdict that the index was 'not much good' would still have been made even if all of the underlying data entering into the composite measures were of the highest quality. But in practice the HDI is far worse than it is in theory, because the quality of many of the data sources used in compiling the measure is quite poor.

The consequences of the use of data on the reliability of the HDI can readily be demonstrated by a comparison of the relative performance of Australia and New Zealand in the 'human development' stakes, as assessed by the UNDP. In the 1997 competition, New Zealand was ranked ninth on the HDI ladder and Australia was ranked 14 th. This overall result was solely attributable to the education component of the HDI, because Australia's ranking was above New Zealand's on both of the other component indexes which went into the overall HDI. Australia ranked equal seventh on the life expectancy index, whereas New Zealand ranked only equal 21st; and Australia was ranked 18th on the real GDP per capita index, whereas New Zealand was 24 th.

Australia's poor showing in the education component of the HDI, vis-a-vis New Zealand's, was in turn, solely attributable to this country's supposedly much lower 'combined first-, second- and third-level gross enrolment ratio'. According

17 Ibid: 19.

18 Dasgupta, Partha (1993). Op cit: 77-8. 
to the Human Development Report which in turn attributed the data to UNESCO, Australia ranked equal 28th (with Poland and Fiji) on this measure, whereas New Zealand ranked fourth in the world in its overall education enrolment ratio. Among the countries which the UNDP ranked above Australia on the education enrolment criterion of human development were Belarus, Libya, Turkmenistan, Peru, South Africa and Namibia.

Fortunately, we have far better data on education enrolment ratios in Australia, New Zealand and other OECD countries than those published by the UNDP. They are compiled by the OECD's Centre for Educational Research and Innovation, and are regularly published in the OECD's Education at a Glance. The most recent issue of this publication ${ }^{19}$ provided estimates of net enrolment rates in all levels of education for each single year of age between the ages of 15 and 24 . These figures show that Australia's education enrolment ratios were higher, not lower, than New Zealand's.

In short, Australia's true HDI rank is well above New Zealand's on all three of the component indexes and, a fortiori, on the composite index. The UNDP'S finding to the contrary is solely a reflection of a statistical aberration in UNESCO data. Yet the UNDP results receive wide coverage in the Australian media, and our politicians and commentators debate the causes of this country's slide down the ladder of human development, including by comparison with New Zealand, as if it were a fact.

Naively, most Australians assume that comparisons which are made in a publication of an arm of the United Nations are reliable and authoritative. How can they be expected to know that Partha Dasgupta, Frank Ramsay Professor of Economics at Cambridge University, considers that the HDI measure is 'not much good'? Or that the comparisons are vitiated by better statistics produced by another international institution?

It must be presumed that, in many other countries, the political and public debate is influenced by naive assessments, made in New York by the Human Development Office of the UNDP, about whether the countries concerned have or have not been successful in translating the benefits of economic growth into improvements in the lives of their people.

Deficiencies in data quality, of the kind which have been illustrated by the Australia/New Zealand example, should be sufficient in themselves to discourage such sweeping and patronising judgements - and one does not have to be knowledgeable about the relevant data to be sure that many of these judgements are unsound.

19 OECD (1996). Education at a Glance: OECD Indicators, (4th ed, issued 9 December 1996): 122. 
There was, for example, a table in the 1997 Human Development Report which showed seven pairs of countries which had, according to the heading, 'similar HDI, different income, 1994'. ${ }^{20}$ The authors failed to reveal the fact that the 'different income' levels were calculated by converting GNP in national currencies to US dollars on the notoriously unsatisfactory basis of prevailing exchange rates. Yet they must have known that the only valid way to measure relative income levels is by correcting for differences in purchasing power, because this is the basis used for the GDP measure which the creators of the HDI used for its 'standard of living' component.

The first of the seven comparisons in the table is between New Zealand and Sweden. New Zealand's slightly higher HDI than Sweden's is set against the 'fact' that Sweden's GNP per capita was 91 per cent higher than New Zealand's in 1994. According to a table showing GDP per capita in purchasing power parity terms for the same year in the same report, ${ }^{21}$ the excess of Sweden's real product per head over New Zealand's was only 13 per cent, not 91 per cent. As average life expectancy in Sweden was higher than in New Zealand, the latter country's higher HDI was entirely attributable to its higher education enrolment ratios in the UNESCO data. Data from the OECD'S Centre for Educational Research and Innovation again show that the figures which were used in the compilation of the HDI are wrong.

The next of the comparisons in the UNDP table shows Barbados as having a higher HDI than Singapore, notwithstanding that Singapore's GNP per capita was well over three times higher than that of Barbados in exchange rate terms and nearly twice as high in purchasing power parity terms. As Singapore's average life expectancy was also higher than its comparator, the supposedly lower level of human development in Singapore is entirely attributable to the education component of the index - and, in particular, to an adult literacy rate of only 91 per cent compared with 97 per cent in Barbados. It is relevant to note that Professor Dasgupta found 'that the adult literacy rate is a rogue index' which was poorly correlated with other 'quality of life' measures, ${ }^{22}$ and it should be obvious in any case that observed differences in adult literacy ratios which exceed 90 per cent would reveal little about contemporary levels of human development.

Similar comments can be made about each of the other comparisons in the UNDP table. The similarity of the HDIs for South Africa and Sri Lanka would be remarkable if GNP per head was indeed nearly five times as great in the former country as in the latter, as the figures in the table wrongly indicate. But

20 UNDP (1997). Op cit: 46.

21 Ibid: 146.

22 Dasgupta, Partha (1993). Op cit: 116. 
it is scarcely worthy of mention if the real margin of difference is only 31 per cent, as the purchasing power parity comparison would have shown it to be. Equally, it would indeed be a matter for remark that Gambia had the same HDI as Mozambique if the former country's GNP per head was really nearly four times as great as the latter. But since the purchasing power parity estimates show both countries as having about the same level of product per head this comparison is again a case of 'Similar HDI, similar income', rather than the reverse phenomenon which the table purports to list.

The UNDP lends itself quite unashamedly to the use of the HDI as a tool for political advocacy. When last year's Human Development Report was launched in Ottawa, the UNDP's news release stated that 'For the third year in a row, the report ... placed Canada at the top of its Human Development Index' and went on to point out that:

The report singles out Canada as a leader in translating economic wealth into the well-being of its citizens, a point which the Hon. Pierre Pettigrew, Minister for International Cooperation, underlined in his comments at the launch. 'In the present context of fiscal restraint,' he said, 'it requires a tremendous amount of political will, consensus and co-operation, at all levels, to continue channelling economic growth into human development through investments in education, health and other public goods, and to ensure that the benefits of growth are equitably shared - both here at home and in developing countries. ${ }^{23}$

The news release for the 1996 launch also stated that the United States ranked second in the HDI, and Japan third. As these two countries also rank among the world's leaders in GDP per head, the results do not sit well with the claim that the HDI provides an alternative to GNP for assessing a country's standing in basic human development. It could be argued, moreover, that an alternative measure to the GDP per head should put the United States and Japan well down the 'league table', because these two countries are frequently believed, including by many of their own citizens, to have failed to translate their economic wealth into a high, and well-distributed, 'quality of life'.

'Quality of life' is a subjective concept. The available indicators of subjective wellbeing are drawn together in the 'World Database of Happiness', which is maintained by the Department of Social Sciences at Erasmus University, Rotterdam in the form of 'a register of scientific research on subjective appreciation of life'. This database provides a comparison of the 'average appreciation of life' in 48 countries in the early 1990s. ${ }^{24}$ The seven countries in

23 UNDP (1997). Press Release 'Human Development Report 1996: Moving from “Inequitable to Inhuman"'. 24 Cited in Wearing, Alexander J and Headey, Bruce (1997). 'Measures and Correlates of Subjective Well Being'. Paper given at the conference 'Measuring National Progress: Is life in Australia getting better, or worse?' Canberra, 3-5 July 1997. 
which the average appreciation of life was highest, according to this measure, were the three Benelux countries, three of the Scandinavian countries (Sweden, Denmark and Iceland) and Ireland. Next, with an equal ranking, were Australia and Switzerland.

As we have seen, the three medal winners in the 1996 HDI Olympics were Canada (gold), the United States (silver) and Japan (bronze). The 'average appreciation of life' in all of these countries was below that in the nine countries which have just been named. Canada, ranked first in 'human development', was 20th out of 48 in 'average appreciation of life'; the United States, ranked second in 'human development', was tenth in 'average appreciation of life'; and Japan, ranked third in 'human development' in 1996 (and first in the early 1990s) was 25th out of 48 in 'appreciation of life'.

It is also of interest to note that New Zealand, which was ranked five places above Australia in the HDI list, was seven places below Australia in the 'appreciation of life' list.

An obvious question which arises from the fact that the HDI is not highly correlated with the subjective measure of 'appreciation of life', is whether there is a higher correlation between 'appreciation of life' and GDP per head, or between 'appreciation of life' and some other objective indicators. For the purposes of this paper, I have attempted to test these relationships for the countries which are included both in the World Bank list of nearly 150 countries (most of which are developing countries) and the 'World Database of Happiness' list of 48 countries (most of which are developed countries). For the 43 countries which figure in both lists, crude measures of correlation were calculated as the average difference between the average 'appreciation of life' rank and the rank on each of the comparator objective indicators, ignoring sign.

According to this test, the objective indicator of wellbeing which correlates best with the subjective measure of wellbeing is GDP per head (an average difference of 7.8 places). This is followed by HDI (an average difference of 8.2 places), life expectancy (an average difference of 8.9 places) and infant mortality (an average difference of 9.6 places). It would be unwise to draw strong inferences from these findings, but it is interesting that an indicator which was never intended to be a measure even of economic welfare should appear to be better correlated with the subjective wellbeing measure than several indicators which embrace non-economic aspects of wellbeing, and also of a composite indicator which was designed to embrace economic and non-economic aspects. 


\section{The Genuine Progress Indicator (GPI)}

The Genuine Progress Indicator (GPI) for the United States was developed in San Francisco by Redefining Progress, an organisation 'whose purpose is to stimulate broad debate over the nature of economic progress and the best means of attaining it'. It was presented in an article in the October 1995 issue of the Atlantic Monthly, entitled 'If the GDP is Up, Why is America Down?' ${ }^{25}$ and a more detailed methodological paper. ${ }^{26}$

The same name has been adopted for indicators with a similar purpose which have subsequently been produced for other countries, including Australia. The Australian indicator, which has been developed by Dr Clive Hamilton, was published recently as a discussion paper by the Australia Institute. ${ }^{27}$

The present paper is concerned with the GPI for the United States. As Dr Hamilton has followed different procedures in developing a GPI for Australia, the discussion which follows does not necessarily apply to his more sophisticated indicator. It is clear that some of the most serious deficiencies in the American GPI have been avoided in the Australian model.

The creators of the United States GPI were extremely critical of the measures of output produced by the world's official statisticians. They held that growth in GDP, as measured by our 'antiquated' national accounting system, is 'an artifact of history', 'a relic of another era' and 'a barricade of abstraction that separates us from economic reality'; and they accused the statisticians of 'rigging the books':

Honest national accounting would inject a large dose of accountability to the political process. It would stop politicians and interest groups from hiding bad policy behind what amounts to a rigged set of books. ${ }^{28}$

The Atlantic Monthly article also included some strong criticism of the economics profession:

... no field has grown more tightly shut than economics, whose basic orthodoxies have persisted for at least a hundred years ... the generation that developed the GDP, and for which the GDP distilled an entire world view, is now mainly retired. The students and disciples of that generation are well into their middle years, rumbling along on mental capital from long ago.

25 Cobb, Clifford et al (1995). 'If the GDP is Up,Why is America Down?', the Atlantic Monthly, Boston, October.

26 Cobb, Clifford et al (1995). The Genuine Progress Indicator: Summary of Data and Methodology, San Francisco.

27 Hamilton, Clive (1997). The Genuine Progress Indicator: A new index of changes in well-being in Australia, Australia Institute, Discussion paper, no. 14, October 1997. 
The uncritical acceptance of the validity of these comments is a telling indicator of the esteem in which the economists and statisticians are held. In an article in The Australian Financial Review in June 1996, Lindsay Tanner, the Federal Shadow Minister for Transport, asserted as a 'basic point' that 'our political and economic analysis is shackled to a system of measurement from the world of Chubby Checker and the FJ Holden'. ${ }^{29}$ And following a presentation by Ted Halstead, the founder and president of Reinventing Progress, at a conference in Canberra last July, ${ }^{30}$ the Canberra Times asserted in an editorial that Mr Halstead had 'persuasively debunked the notion that GDP is a useful measure of a nation's real economic wealth or well-being', and that this measure 'says nothing about the quality of life enjoyed by citizens' (emphases added). ${ }^{31}$

It is a moot point whether the GPI is useful in measuring wellbeing, or says something about the quality of life. Its creators have a rare faith in numbers. For example, they hold that television viewing contributes to family breakdown, turning children 'into ardent, GDP-enhancing consumers'. As 'Even those unwed teenage mothers are bringing new little consumers into the world', a negative adjustment was made to the GPI to allow for the genuine regress which was assumed to result from television watching by children. The adjustment was calculated as follows:

... we estimated the time involved in these families as hours per day per household) times (365 days per year) times (number of households in the US) times (the proportion of households with children) times (\$0.30). ${ }^{32}$

Another negative adjustment was made for 'divorce', which was calculated by multiplying the number of divorces in the United States by $\$ 5000$ and the number of children affected by $\$ 7500$, as 'a rough estimate of lifetime damage including such things as counselling, health costs and difficulties at school, work and in personal relationships'.

These are precisely the kinds of adjustments which the economist Arthur Okun, in a 1971 paper, strongly urged national accountants to 'resist at all costs':

It is hard to understand how anyone could seriously believe that GNP could be converted into a meaningful indicator of total social welfare. Obviously, any number of things could make the nation better off without raising its real GNP as measured today: we might start the list with peace, equality of opportunity, the elimination of injustice and violence, greater brotherhood among Americans of different racial and

29 Tanner, Lindsay (1996). 'Time for an indicator of real progress' in Australian Financial Review, 4 June 1996.

30 Halstead, Ted (1997). The Science and Politics of New Measures of Progress: A United States Perspective',

presented at Conference on 'Measuring National Progress', Canberra, 3 July.

31 The Canberra Times, (1997). 'Food for thought on the economy', 7 July.

32 Ibid: 21. 
ethnic backgrounds, better understanding between parents and children and between husbands and wives, and we could go on endlessly. To suggest that GNP could become the indicator of social welfare is to imply that an appropriate price tag could be put on changes in all of these social factors from one year to the next. This is ... asking the national income statistician to play the role of a philosopher-king, quantifying and evaluating all changes in the human scene (emphasis in original). ${ }^{33}$

A detailed commentary on the criticisms of the GDP by the creators of the GPI, and a detailed evaluation of the GPI itself, would require a lengthy paper in itself. All that will be attempted here is a comparison of how the two concepts handle one key issue: the measurement of the interaction of the government and non-government sectors. This was, of course, the central aspect of the working of a mixed economy which the system of national accounts was devised to illuminate.

The conventional national accounts include in GDP the expenditure of government. The reason for this was explained in JR Hicks' seminal paper entitled 'The Valuation of the Social Income':

... if we accept the actual choices of the individual consumer as reflecting his preferences (clearly we must do so for these purposes), then I do not see that we have any choice but to accept the actual choices of the government, even if they are expressed through a Nero or a Robespierre, as representing the actual wants of society. ${ }^{34}$

By contrast, 'the GPI does not include most government expenditures'. The creators of the GPI explain that

The main reason is that [government expenditures] are largely defensive in nature; they protect against erosions in the quality of life, rather than enhancing that quality of life. (This is literally the case regarding the largest government service outlay, defence. $)^{35}$

The counter argument to this view of the San Francisco think-tank in 1995 was mounted by Nassau Senior, first professor of political economy at Oxford University, in his lectures at Oxford in 1828:

Those writers who have maintained that whatever is raised by taxation is deducted from the revenue of the country, seem to have been led to this conclusion by observing that the object of government is to occasion not positive but negative effects, not to produce good, but to

33 Okun, Arthur M (1971). 'Social Welfare Has No Price Tag' in United States, Department of Commerce, Survey of Current Business, 50th Anniversary Issue, July 1971: 129-30.

34 Hicks, JR (1940). 'The Valuation of the Social Income' in Economica, May 1940.

35 Cobb, Clifford, et al (1995). Op cit: 16. 
prevent evil...But it must be recollected that the mere prevention of evil is one of the principal objects even of individual expenditure. We do not build houses because it is pleasant to breathe the confined atmosphere of a room, but because roofs and walls are the only means by which the inclemency of the seasons can be avoided. We do not buy drugs for our pleasure, but to avert or remove disease. Yet no one ever thought what he spends on medicines and on house rent a deduction from his income. ...

And it may be asked, in what respect does each man's contribution towards the means by which the community is to be protected against internal and external violence and fraud differ from his contribution to a Friendly Society ... ? It is true that, if the protection could be less expensively obtained, the fund for the maintenance of labour would be increased. But this is merely an exemplification of [the principle] that the extent of the fund for the maintenance of labour depends mainly on the productiveness of labour. If fewer fleets, and armies and magistrates could preserve the peace, ... the labouring classes would, ceteris paribus, be better off, just as they would be better off if fewer husbandmen or artisans could produce ... the same quantity of corn; that is, if labour were more productive in supplying food. ${ }^{36}$

Commenting on the argument that 'regrettable necessaries' should be excluded from GDP, Edward Denison was to make a similar point in 1971:

It yields the false result that we are equally well off whether, in the same circumstances, we ride or must walk to work, freeze or are comfortable, do or do not obtain medical care when we are sick, or provide or do not provide for national security. Needs and provision to meet them must be separately evaluated. ${ }^{37}$

Not all of the propositions mounted by Senior in 1828 and Denison in 1971 are beyond argument. Some of them have, indeed, continued to be argued within the profession whose basic orthodoxies are supposed by the creators of the GPI to have persisted for at least 100 years. In this case, the orthodoxy has persisted for closer to 200 years, but that does not mean it is immutable.

In the meantime, those who support the exclusion of the expenditure of government from the measure of progress should know the implications of this exclusion.

36 Senior, MW (1858). Political Economy, London: 183

37 Denison, Edward (1971). In Survey of Current Business, January 1971: 15. Cited in Okun, Arthur M (1971), op cit: 132. 
One implication, of course, is that 'genuine progress' according to the GPI will occur whenever the provision of services by government is replaced by private provision. For example, if the entire system of publicly provided schools in the United States were to be privatised, and parents were obliged to pay for their children to be educated in the same way as they are now obliged to pay for them to be fed, the GPI would record a huge leap in 'genuine progress' because of the resulting rise in private consumption. The GDP would not be significantly affected, because in this case the increase in expenditure on private consumption would be substantially offset by a corresponding decrease in government consumption expenditure.

Some technical consequences of the GPI treatment of government expenditure should be noted. At present, most children in the United States attend schools operated by government authorities. This means that expenditure on the salaries of most of the nation's school-teachers is entered into the GPI calculation at zero. The number of hours worked by some of these teachers is greater than the number that they are presumed to wish to work, in which case the GPI requires a deduction from the zero figure. Other teachers work fewer hours than they would prefer, and in this case the GPI again registers a negative figure, even though there is no positive figure from which to make the deduction. Again, most teachers at public schools incur expenditures in travelling to work, and the time that they spend on commuting is not available for them to spend on other activities: under the GPI methodology these commuting costs are also deducted from incomes which have not been counted in the first place.

Yet the creators of the GPI maintain that it is the GDP which is 'a barricade of abstraction that separates us from economic reality'.

Another consequence of the GPI treatment of government activity needs to be noted. The GPI rises if a government introduces or raises substantially the charges for entry into museums or national parks, because the GPI assumes that only private spending can achieve 'genuine progress': government spending on (say) national parks is, in the view of the GPI's creators, only preventing regress. Yet it should be obvious that output is the same, whether the government's expenditure on national parks is financed by charges on users or by taxation.

Again it is difficult to contest the proposition that it is the GDP which records the 'economic reality', and that it is the GPI which fails to provide 'an honest set of books'.

One final point needs to be made. The proponents of the HDI and the GPI have criticised the concepts of the economists and the national accounts statisticians in strong terms, but they have shown little inclination to submit their alternative concepts to critical scholarly scrutiny, or to acknowledge and respond to the 
substantial criticisms which have been made. In this field, the economists and national accountants have maintained a tradition of open inquiry since Sir William Petty invited 'all ingenious and candid persons' to rectify the 'errors, defects and imperfections' in the argument of his Political Arithmetick in 1676.

The conferences of the International Association for Research in Income and Wealth (IARIW) and the Association's Journal Review of Income and Wealth provide fora in which the issues discussed in this paper are regularly and freely debated. A paper in the September 1996 issue of the Review by Markos Mamalakis of the University of Wisconsin deserves special mention. Its subject is indicated adequately by its title: 'Misuse and Use of National Accounts as a Welfare Indicator: Selected Analytical and Measurement Issues'. Mamalakis' abstract indicates that his

...evaluation of deductions and additions to the System of National Accounts (SNA) made by [a number of scholars] in their research on extended product and income accounts and improved indicators of welfare reveals numerous unresolved analytical and measurement issues; and reaffirms the usefulness of the SNA as a fundamental, initial, welfare indicator (emphasis added). ${ }^{38}$

For a statistician who was formerly responsible for Australia's national accounts, and who believed himself to be producing 'an honest set of books', this is a reassuring conclusion.

38 Mamalakis, Markos J (1996). 'Misuse and Use of National Accounts as a Welfare Indicator: Selected Analytical and Measurement Issues', Review of Income and Wealth, September 1996: 293. 